\title{
Biomarkers: Evaluation of Screening for and Early Diagnosis of Hepatocellular Carcinoma in Japan and China
}

\author{
Peipei Song Jianjun Gao Yoshinori Inagaki Norihiro Kokudo \\ Kiyoshi Hasegawa Yasuhiko Sugawara Wei Tang \\ Hepato-Biliary-Pancreatic Surgery Division, Department of Surgery, Graduate School of \\ Medicine, The University of Tokyo, Tokyo, Japan
}

\section{Key Words}

Tumor marker • Des- $\gamma$-carboxyprothrombin $\cdot \alpha$-Fetoprotein $\cdot$ Lens culinaris agglutinin-reactive fraction of $\alpha$-fetoprotein

\begin{abstract}
Over the past few decades, the screening for and early diagnosis of hepatocellular carcinoma (HCC) has attracted attention worldwide, and especially in Asian countries such as Japan and China. Such approaches can help detecting HCC at an earlier stage when curable interventions can be offered to achieve long-term disease-free survival for patients. Biomarkers have been used to screen for and diagnose HCC in various countries. In Japan, the combined tests of des- $\gamma$-carboxyprothrombin (DCP) and $\alpha$-fetoprotein (AFP) or Lens culinaris agglutinin-reactive fraction of AFP (AFP-L3) have been shown to achieve a high level of sensitivity and specificity. These tests have routinely been used to screen for HCC and are covered by Japan's national health insurance. Due to the routine practice of screening for HCC among high-risk patients, HCC nodules have been detected in the early stages in more than $60 \%$ of patients in Japan. In contrast, although several remarkable advances in the management of HCC have been made in China over the past few decades, most HCC patients still present with advancedstage disease. AFP is the only serum biomarker that has widely been used to screen for and diagnose HCC in China. In recent years, several molecular biological studies have further investigated the clinical usefulness of DCP, and they have found that it may facilitate the screening for and diagnosis of HCC and assist with the assessment of HCC progression. DCP can serve as a biomarker to detect HCC in an early stage and facilitate definitive treatment. The wide implementation of DCP is expected, especially in China where $55 \%$ of HCC cases worldwide live.




\section{Liver Cancer}

\section{Introduction}

Hepatocellular carcinoma (HCC) is the fifth most common cancer and the third leading cause of cancer-related deaths worldwide. Asian countries account for $75-80 \%$ of the roughly 650,000 HCC cases reported globally each year. Of particular note is the fact that China alone accounts for $55 \%$ of HCC cases worldwide $[1,2]$. In Japan, HCC ranks as the third leading cause of cancer-related deaths in males and the fifth leading cause of cancer-related deaths in females. More than 30,000 patients die of HCC every year [3, 4]. Over the past 10 years, HCC management in Japan has achieved remarkable results because of the wide acceptance and implementation of the 'Japanese Evidence-Based Clinical Practice Guideline for HCC' (J-HCC Guideline) [5] and the 'Expert Consensus on HCC by the Japan Society of Hepatology' (JSH Guideline) [6], with a combination of quantitative and qualitative evaluation incorporated in the guidelines [7]. Specifically, HCC nodules have been detected in the early stage in more than $60 \%$ of patients due to the routine practice of screening for HCC among high-risk patients in Japan [8]. In China, HCC ranks as the second leading cause of cancer-related deaths in males and the third leading cause of cancer-related deaths in females. The incidence of HCC is increasing in China, and HCC is the second most common cancer in urban areas and first most common in rural areas [9]. Several remarkable advances have been made in HCC management in China over the past few decades, such as 'The Expert Consensus on the Treatment Standards for Hepatology Carcinoma' (Chinese Guideline) published in 2009 [10]. However, most HCC patients in China still present with advanced-stage disease [11].

Currently, surgical resection and liver transplantation offer the best potential for treating HCC [12-14] but are only available to patients whose tumors are detected early. Such patients currently account for only $10-20 \%$ of cases [15]. Thus, strategies have been adopted to screen for and diagnose HCC at an earlier stage when curable interventions can be offered to achieve long-term disease-free survival for patients [16].

\section{The Current Status of Screening for and Early Diagnosis of HCC in Japan and China}

\section{Strategies to Screen for and Diagnose HCC}

There are many differences in HCC screening and early diagnosis between Japan and China (table 1). In Japan, more than $70 \%$ of patients with HCC are infected with hepatitis C virus (HCV), and approximately $15-20 \%$ of patients are infected with hepatitis B virus (HBV) [17]; these figures are similar to those reported from the United States and Europe $[18,19]$. In contrast, approximately $85 \%$ of Chinese HCC cases are HBV related, $10 \%$ of cases are HCV related, and some cases involve HBV and HCV superinfection [9, 20]. Several cohort studies have shown that screening high-risk patients with HBV- or HCV-related chronic liver diseases improves the rate of early HCC detection and the rate of curative treatment [21-24]. Many guidelines for HCC treatment recommend HCC screening, including the guidelines established by the American Association for the Study of Liver Disease (AASLD) [25], the National Comprehensive Cancer Network (NCCN) [26], and the Asian Pacific Association for the Study of the Liver (APASL) [27].

Screening tools should have an acceptable rate of accuracy and should be affordable. In general, the tests used to screen for HCC in different countries depend on imaging technology and biomarkers [28, 29]. Ultrasound (US) is the imaging technique most often used to screen for HCC because it is simple, inexpensive, and noninvasive and allows real-time observation. However, the success of US depends on the expertise of the physician, the US equipment available, and the echo texture of the liver; thus, the actual sensitivity of US is difficult to assess due to the lack of a definitive standard for HCC [27, 30]. Currently, the 


\section{Liver
Cancer}

\begin{tabular}{|c|c|}
\hline \multicolumn{2}{|l|}{ Liver Cancer 2013;2:31-39 } \\
\hline $\begin{array}{l}\text { DOI: } 10.1159 / 000346220 \\
\text { Published online: January 7, } 2013\end{array}$ & $\begin{array}{l}\text { (c) } 2013 \text { S. Karger AG, Basel } \\
\text { www.karger.com/lic }\end{array}$ \\
\hline
\end{tabular}

Table 1. The current status of HCC screening and early diagnosis in Japan and China

\begin{tabular}{llll}
\hline Variables & Japan & China & References \\
\hline $\begin{array}{l}\text { Leading cause of } \\
\text { cancer-related deaths }\end{array}$ & Third in males, fifth in females & Second in males, third in females & {$[3,4,9]$} \\
\hline Etiological factors & $\begin{array}{l}\text { 70\% of patients with HCV infection, } \\
\text { 15-20\% of patients with HBV infection }\end{array}$ & $\begin{array}{l}\text { 85\% of patients with HBV infection, } \\
10 \% \text { of patients with HCV infection }\end{array}$ & {$[9,15,18]$} \\
\hline $\begin{array}{l}\text { Government-funded } \\
\text { nationwide screening } \\
\text { program }\end{array}$ & Established in 2002 for patients over & No & {$[11,25$,} \\
& 40 years with HCV/HBV infection & & $46,47]$ \\
High-risk group & High-risk group: patients with HBV/HCV & Patients infected with HBV, HCV, or & {$[5,10$,} \\
& infection or cirrhosis due to other causes; & HBV and HCV superinfection and patients & $48,49]$ \\
& Very-high-risk group: patients with & with cirrhosis, alcohol abuse, diabetes & \\
& HBV-/HCV-related cirrhosis & mellitus, or a family history of HCC; & \\
& & Patients aged 35-40 years & {$[6,8,10,49$,} \\
\hline Screening tool & US and combined test of DCP and AFP & US and AFP & $50]$ \\
\hline Screening criteria & 3-4 months for very-high-risk group; & 6-month intervals for high-risk group & {$[5,6,8,10$,} \\
& 6-month intervals for high-risk group & & $48,50]$ \\
\hline Diagnosis & Dynamic CT/MRI for definitive diagnosis; & US/CT/MRI, AFP, and biopsy for & {$[5,10$,} \\
& DCP/AFP/AFP-L3 for adjunctive diagnosis & differential diagnosis & $49,50]$ \\
\hline $\begin{array}{l}\text { Early detection } \\
\text { (reference) }\end{array}$ & $>$ 60\% of HCC detected by national & Most patients with HCC present with & {$[8,11]$} \\
\hline & Screening in the early stages & advanced-stage disease & \\
\hline
\end{tabular}

combination of US and $\alpha$-fetoprotein (AFP) measurement is widely accepted and implemented as a screening strategy. This approach offers an increased possibility to detect small HCC compared to US or AFP measurement alone [31-33].

AFP has a sensitivity and specificity for detecting HCC in the range of $41-65 \%$ and $80-90 \%$, respectively, when an AFP cut-off of $20 \mathrm{ng} / \mathrm{ml}$ is used [34]. However, up to $50 \%$ of patients with HCC have an AFP level below $20 \mathrm{ng} / \mathrm{ml}$ [35], thus AFP cannot be used as the sole tool to screen for HCC. There are two other biomarkers besides AFP to screen for HCC, namely des- $\gamma$-carboxyprothrombin (DCP, also known as prothrombin induced by vitamin $\mathrm{K}$ absence-II, PIVKA-II) and Lens culinaris agglutinin-reactive fraction of AFP (AFP-L3) [36, 37]. Many studies have compared the clinical usefulness of these three biomarkers, but the final conclusions are still being discussed. However, multiple reports have shown that a combination of DCP and AFP or AFP-L3 is more effective in detecting HCC at present [38-41].

When a nodule is detected in screening, a differential diagnosis is made. The choice of diagnostic tools depends on the diameter of the nodule, i.e. $<1,1-2$, or $>2 \mathrm{~cm}$. This criterion is recommended by many countries' guidelines for HCC [7]. In general, the tests used to diagnose HCC in different countries include diagnostic imaging, serological diagnosis, and histological diagnosis. Diagnostic imaging techniques include US, computed tomography (CT), and magnetic resonance imaging (MRI). According to a systematic review, US has a sensitivity of $60 \%$ and a specificity of $97 \%$, CT has a sensitivity of $68 \%$ and a specificity of 93\%, and MRI has a sensitivity of $81 \%$ and a specificity of $85 \%$ [42]. Techniques for serological diagnosis such as AFP measurement have widely varying sensitivity and specificity, and the guidelines for HCC in some countries such as the UK and South Korea recommend that these techniques should be used as an adjunct diagnostic tool $[43,44]$. Histological diagnosis can be 
done by a biopsy (also known as fine needle aspiration cytology, FNAC), which has an overall sensitivity of $95.2 \%$ and a specificity of $100 \%[45,46]$; however, biopsies should be avoided if curative surgery is planned because there is a slight chance $(2.7 \%)$ of needle-track tumor seeding following a biopsy. This holds true unless a biopsy might affect patient management or imaging techniques and AFP fails to resolve doubts about the diagnosis $[47,48]$.

\section{The Current Status of Screening for and Diagnosis of HCC in Japan}

In 2002, Japan's Ministry of Health, Labor, and Welfare started a national 5-year program to screen for HCV and HBV infection among people over 40 years given the high prevalence of HCV infection in this age group [49,50]. By the end of 2006, 9 million people had been screened. Of these, 112,000 were found to have HCV infection and 110,000 were found to have HBV infection [27]. Since most high-risk patients were closely followed before developing HCC, HCC nodules were detected in the early stage in more than $60 \%$ of patients in Japan [8].

Currently, AFP, AFP-L3, and DCP are widely and routinely used to screen for HCC in Japan, and these tests are covered by Japan's national health insurance as serological biomarkers to screen for HCC in clinical settings [29]. According to the J-HCC Guideline, the first evidence-based clinical practice guidelines for HCC in Japan, AFP, AFP-L3, and DCP should be measured at intervals of 3-4 months in the very-high-risk group (patients with HBV- or HCV-related liver cirrhosis) and at 6-month intervals in the high-risk group (patients with HBV- or HCV-related chronic liver disease or liver cirrhosis due to other causes) [5, 51, 52]. The J-HCC Guideline and JSH Guideline strongly recommend the periodic and simultaneous measurement of DCP and AFP or AFP-L3 levels to screen for patients with HCC and to detect small HCC with a high level of sensitivity and specificity $[6,8,52,53]$. A total of 200 Japanese experts were surveyed in 2009 to determine the nature of HCC screening in Japan. The survey found that $72 \%$ of these experts simultaneously measured the tumor markers of AFP, APF-L3, and DCP, and 44\% of the experts combined this measurement with US [54].

Many Western guidelines for diagnosing HCC recommend a definitive diagnosis reached by using different diagnostic tools to determine the nodular diameter [7]. In contrast, the J-HCC Guideline and JSH Guideline in Japan recommend that HCC should be diagnosed by characteristic features (hypervascularity in the arterial phase and washing out in the portal venous phase) on dynamic CT or dynamic MRI, regardless of the tumor size $[52,53]$. This approach has a sensitivity of $68-91 \%[55,56]$ and a specificity of $77-100 \%[57,58]$.

If US suggests a new nodular lesion in screening in Japan, dynamic CT or dynamic MRI will be performed to make a differential diagnosis; if the AFP level rises continuously or has increased to $200 \mathrm{ng} / \mathrm{ml}$ or more, the DCP level is at least $40 \mathrm{mAU} / \mathrm{ml}$, or the AFP-L3 fraction is $15 \%$ or more, dynamic CT/MRI will be considered, even if US shows no evidence of a tumor $[5,52]$.

\section{The Current Status of Screening for and Early Diagnosis of HCC in China}

Like Japan, Taiwan has established a screening program that screens patients with cirrhosis every 3-6 months and patients with no cirrhosis every 6-12 months; there is no age limit for screening of HBV carriers in Taiwan. However, there is no government-funded screening program for HCC in Hong Kong or other parts of China [11].

In China, the high-risk group for HCC includes patients chronically infected with HBV, HCV, or HBV and HCV superinfection and patients with cirrhosis, alcohol abuse, diabetes mellitus, or a family history of HCC. For patients aged 35-40 years, AFP and US should be performed every 6 months according to the Chinese Guideline [10]. If the AFP level rises continuously or US suggests a new nodular lesion, a differential diagnosis will be made based on diagnostic imaging, serological diagnosis, or histological diagnosis. 


\section{Liver Cancer}

\begin{tabular}{|c|c|}
\hline \multicolumn{2}{|l|}{ Liver Cancer 2013;2:31-39 } \\
\hline $\begin{array}{l}\text { DOI: } 10.1159 / 000346220 \\
\text { Published online: January 7, } 2013\end{array}$ & $\begin{array}{l}\text { (c) } 2013 \text { S. Karger AG, Basel } \\
\text { www.karger.com/lic }\end{array}$ \\
\hline
\end{tabular}

At present, AFP measurement and US at 6-month intervals are the standard tools to screen for HCC in China. AFP is considered to be a useful and feasible tool for screening and early diagnosis in China due to its convenience and especially due to the fact that more than $60 \%$ of patients with HCC have an AFP level of $>400 \mathrm{ng} / \mathrm{ml}$ [10]. The clinical usefulness of AFP in China has been confirmed by a randomized controlled trial involving 18,816 patients aged 35-59 years with HBV infection or a history of chronic hepatitis. The patients were randomly assigned to a screening $(9,373)$ or control $(9,443)$ group undergoing AFP measurement and US every 6 months. The results showed that biannual screening with AFP and US significantly reduced mortality. Screened patients had a survival rate of $65.9 \%$ at 1 year, $52.6 \%$ at 3 years, and $46.4 \%$ at 5 years versus $31.2 \%$ at 1 year, $7.2 \%$ at 3 years, and $0 \%$ at 5 years for unscreened patients [59].

Many studies have strongly recommended the combined testing of DCP and AFP or AFP-L3 to screen for patients with HCC and to detect small HCC with a high level of sensitivity and specificity, but DCP testing is currently approved only in Japan, South Korea, and Indonesia [60]. In order to assess the screening and diagnostic value of DCP in Chinese patients with HCC, a study was conducted in China in 2002 to determine DCP and AFP levels in 60 patients with HCC and 30 patients with cirrhosis but no HCC [61]. This study found no significant correlation between serum levels of DCP and AFP in the 60 patients with HCC $\left(\mathrm{r}_{\mathrm{s}}=1.101\right.$, $\mathrm{p}=0.247)$. DCP had a sensitivity of about $51.7 \%$ and a specificity of about $86.7 \%$, while the combined tests of DCP and AFP had a sensitivity of 78.3\%, which is higher than that of DCP alone (51.7\%) and AFP alone (56.7\%). Another study to assess the clinical usefulness of DCP in Chinese patients with HCC was reported in 2003 [62]. This study involved 120 patients with HCC and 90 patients with cirrhosis. No significant correlation between serum levels of DCP and AFP in the 120 patients with HCC was found $\left(r_{s}=1.106, p=0.249\right)$. DCP had a sensitivity of $53.3 \%$ and a specificity of $85.6 \%$, while the combined tests of DCP and AFP had a sensitivity of 78.3\%, which is higher than that of DCP (53.3\%) and AFP alone (58.3\%).

Two studies found DCP to be a useful biomarker to screen for and diagnose HCC, and these studies found that sensitivity may improve when DCP is combined with AFP in Chinese patients. Such work provides a better perspective on the use of DCP to detect HCC in the early stage. However, these studies were small in scale and involved few Chinese patients. Large-scale and multicenter studies of Chinese patients are needed to provide more data and corroborate earlier findings. The good news is that a program was launched by the Japan-China Joint Team for Medical Research and Cooperation on HCC in 2012 to assess the clinical usefulness of DCP in Chinese patients through a large-scale, multicenter study. This study found no significant correlation between serum levels of DCP and AFP. DCP may have a specificity as high as $90 \%$, and the combined tests of DCP and AFP have a significantly higher sensitivity compared to AFP alone in Chinese patients.

\section{Prospects of Biomarkers for HCC in Japan and China}

As noted earlier, biomarkers have been widely used to screen for and diagnose HCC in both Japan and China. The difference is that the combined tests of DCP and AFP or AFP-L3 have been routinely used to screen for HCC in Japan and are covered by Japan's national health insurance. In contrast, some studies have been conducted to assess the clinical usefulness of DCP in Chinese patients, but AFP is the only serum biomarker that has been widely used to screen for and diagnose HCC in China until now.

Although AFP is the most widely used biomarker of HCC, total AFP is not always specific for HCC $[42,63]$, and elevated levels of AFP are also found in patients with liver diseases other than HCC, including viral hepatitis, at a rate of 10-42\% [64-66]. In contrast, AFP-L3 
and DCP are very specific for HCC, compared to AFP alone [67, 68]. In 1984, Liebman et al. [69] first reported DCP in the plasma of $90 \%$ of patients with HCC. Since then, substantial evidence has been assembled through numerous clinical trials, and studies have demonstrated the clinical usefulness of serum DCP levels in screening for patients with HCC [7073]. Some studies have found that the combined test of DCP and AFP has a sensitivity of $84 \%$ and a specificity of $83 \%$. The combined test of DCP and AFP-L3 has a sensitivity of 89.5$89.8 \%$ and a specificity of $41.7-66.7 \%$ when detecting small HCC with a tumor diameter of $\leq 3 \mathrm{~cm}[41,74-76]$.

Furthermore, Tang's research group [77-85] has recently investigated the potential clinical usefulness of DCP in assessing HCC progression. They found that: (i) positivity for serum DCP was significantly related to the presence of vascular invasion, intrahepatic metastasis, tumor size, and TNM stage as well as a high frequency of tumor recurrence, indicating that DCP could serve as an indicator of HCC recurrence after curative therapy; (ii) a high level of DCP is a good predictor of the presence of vascular invasion and could be used to select recipients of liver transplants, and (iii) the use of an inhibitor of DCP in multidrug chemotherapy may induce antiproliferative and antiangiogenic action, indicating that DCP may facilitate the development of new chemotherapeutic strategies for treating HCC.

\section{Conclusion}

DCP is considered to be a useful serum biomarker to screen for and diagnose HCC. Many studies have strongly recommended the combined testing of DCP and AFP or AFP-L3, and these tests have been routinely used to screen individuals for HCC in Japan and to sensitively and specifically detect HCC in the early stages. Until now, AFP is the only serum biomarker that has been widely used to screen for and diagnose HCC in China. Currently, more largescale and multicenter studies are desperately needed to assess the clinical usefulness of DCP in Chinese patients. The potential clinical usefulness of DCP needs to be investigated in terms of screening for and early diagnosis of HCC and also in terms of its treatment. DCP can help to detect HCC in the early stages and facilitate definitive treatment. The wide implementation of DCP is expected, especially for China that accounts for $55 \%$ of HCC cases worldwide.

\section{Acknowledgements}

This work was supported by Grants-in-Aid from the Japan Society for the Promotion of Science and the Ministry of Education, Culture, Sports, Science and Technology of Japan.

\section{Conflict of Interest}

No conflicts of interest to disclose.

\section{References}

1 Prevention of hepatocellular carcinoma in the Asia-Pacific region: consensus statements. J Gastroenterol Hepatol 2010;25:657-663.

2 Yuen MF, Hou JL, Chutaputti A; Asia Pacific Working Party on Prevention of Hepatocellular Carcinoma: Hepatocellular carcinoma in the Asia pacific region. J Gastroenterol Hepatol 2009;24:346-353.

3 Ikai I, Arii S, Okazaki M, Okita K, Omata M, Kojiro M, et al: Report of the 17th Nationwide Follow-up Survey of Primary Liver Cancer in Japan. Hepatol Res 2007;37:676-691. 
- 4 Chung H, Ueda T, Kudo M: Changing trends in hepatitis C infection over the past 50 years in Japan. Intervirology 2010;53:39-43.

5 Makuuchi M, Kokudo N, Arii S, Futagawa S, Kaneko S, Kawasaki S, et al: Development of evidence-based clinical guidelines for the diagnosis and treatment of hepatocellular carcinoma in Japan. Hepatol Res 2008; 38:37-51.

- 6 Kudo M, Okanoue T, Japan Society of Hepatology: Management of hepatocellular carcinoma in Japan: consensus-based clinical practice manual proposed by the Japan Society of Hepatology. Oncology 2007; 72(suppl 1):2-15.

- 7 Song P, Tang W, Tamura S, Hasegawa K, Sugawara Y, Dong J, et al: The management of hepatocellular carcinoma in Asia: a guideline combining quantitative and qualitative evaluation. Biosci Trends 2010;4: 283-287.

8 Izumi N: Diagnostic and treatment algorithm of the Japanese society of hepatology: a consensus-based practice guideline. Oncology 2010;78(suppl 1):78-86.

- 9 Tanaka M, Katayama F, Kato H, Tanaka H, Wang J, Qiao YL, et al: Hepatitis B and C virus infection and hepatocellular carcinoma in China: a review of epidemiology and control measures. J Epidemiol 2011;21:401416.

10 Song PP, Tobe RG, Inagaki Y, Kokudo N, Hasegawa K, Sugawara Y, Tang W: The management of hepatocellular carcinoma around the world: a comparison of guidelines from 2001 to 2011. Liver Int 2012;32:10531063.

11 Kudo M, Han KH, Kokudo N, Cheng AL, Choi BI, Furuse J, et al: Liver Cancer Working Group report. Jpn J Clin Oncol 2010;40(suppl 1):i19-i27.

$\checkmark 12$ Gao JJ, Song PP, Tamura S, Hasegawa K, Sugawara Y, Kokudo N, et al: Standardization of perioperative management on hepato-biliary-pancreatic surgery. Drug Discov Ther 2012;6:108-111.

13 Belghiti J, Fuks D: Liver resection and transplantation in hepatocellular carcinoma. Liver Cancer 2012;1: 71-82.

14 Cheah YL, Chow P: Liver transplantation for hepatocellular carcinoma: an appraisal of current controversies. Liver Cancer 2012, in press.

15 Llovet JM, Burroughs A, Bruix J: Hepatocellular carcinoma. Lancet 2003;362:1907-1917.

16 Forner A, Llovet JM, Bruix J: Hepatocellular carcinoma. Lancet 2012;379:1245-1255.

17 Ikai I, Itai Y, Okita K, Omata M, Kojiro M, Kobayashi K, et al: Report of the 15th follow-up survey of primary liver cancer. Hepatol Res 2004;28:21-29.

18 Marrero JA, Pelletier S: Hepatocellular carcinoma. Clin Liver Dis 2006;10:339-351, ix.

19 Cabrera R, Nelson DR: Review article: the management of hepatocellular carcinoma. Aliment Pharmacol Ther 2010;31:461-476.

-20 Yuen MF, Hou JL, Chutaputti A: Hepatocellular carcinoma in the Asia pacific region. J Gastroenterol Hepatol 2009;24:346-353.

21 Yuen MF, Cheng CC, Lauder IJ, Lam SK, Ooi CG, Lai CL: Early detection of hepatocellular carcinoma increases the chance of treatment: Hong Kong experience. Hepatology 2000;31:330-335.

22 Chen TH, Chen CJ, Yen MF, Lu SN, Sun CA, Huang GT, et al: Ultrasound screening and risk factors for death from hepatocellular carcinoma in a high risk group in Taiwan. Int J Cancer 2002;98:257-261.

23 Bolondi L, Sofia S, Siringo S, Gaiani S, Casali A, Zironi G, et al: Surveillance programme of cirrhotic patients for early diagnosis and treatment of hepatocellular carcinoma: a cost effectiveness analysis. Gut 2001;48: 251-259.

24 Danta M, Barnes E, Dusheiko G: The surveillance and diagnosis of hepatocellular carcinoma. Eur J Gastroenterol Hepatol 2005;17:491-496.

25 Bruix J, Sherman M: Management of hepatocellular carcinoma. Hepatology 2005;42:1208-1236.

-26 Benson AB 3rd, Abrams TA, Ben-Josef E, Bloomston PM, Botha JF, Clary BM, et al: NCCN clinical practice guidelines in oncology: hepatobiliary cancers. J Natl Compr Canc Netw 2009;7:350-391.

27 Omata M, Lesmana LA, Tateishi R, Chen PJ, Lin SM, Yoshida H, et al: Asian Pacific Association for the Study of the Liver consensus recommendations on hepatocellular carcinoma. Hepatol Int 2010;4:439-474.

-28 Barletta E, Tinessa V, Daniele B: Screening of hepatocellular carcinoma: role of the alpha-fetoprotein (AFP) and ultrasonography (in Italian). Recenti Prog Med 2005;96:295-299, quiz 328.

29 Kudo M: Japan's successful model of nationwide hepatocellular carcinoma surveillance highlighting the urgent need for global surveillance. Liver Cancer 2012, in press.

-30 Amarapurkar D, Han KH, Chan HL, Ueno Y: Application of surveillance programs for hepatocellular carcinoma in the Asia-Pacific Region. J Gastroenterol Hepatol 2009;24:955-961.

-31 McMahon BJ, Bulkow L, Harpster A, Snowball M, Lanier A, Sacco F, et al: Screening for hepatocellular carcinoma in Alaska natives infected with chronic hepatitis B: a 16-year population-based study. Hepatology 2000;32:842-846.

-32 Toyoda H, Kumada T, Kiriyama S, Sone Y, Tanikawa M, Hisanaga Y, et al: Impact of surveillance on survival of patients with initial hepatocellular carcinoma: a study from Japan. Clin Gastroenterol Hepatol 2006;4: 1170-1176.

-33 Thompson Coon J, Rogers G, Hewson P, Wright D, Anderson R, Cramp M, et al: Surveillance of cirrhosis for hepatocellular carcinoma: systematic review and economic analysis. Health Technol Assess 2007;11: $1-206$. 
-34 Daniele B, Bencivenga A, Megna AS, Tinessa V: Alpha-fetoprotein and ultrasonography screening for hepatocellular carcinoma. Gastroenterology 2004;127(5 suppl 1):S108-S112.

-35 Farinati F, Marino D, De Giorgio M, Baldan A, Cantarini M, Cursaro C, et al: Diagnostic and prognostic role of alpha-fetoprotein in hepatocellular carcinoma: both or neither? Am J Gastroenterol 2006;101:524-532.

-36 Sassa T, Kumada T, Nakano S, Uematsu T: Clinical utility of simultaneous measurement of serum highsensitivity des-gamma-carboxy prothrombin and Lens culinaris agglutinin A-reactive alpha-fetoprotein in patients with small hepatocellular carcinoma. Eur J Gastroenterol Hepatol 1999;11:1387-1392.

-37 Ikoma J, Kaito M, Ishihara T, Nakagawa N, Kamei A, Fujita N, et al: Early diagnosis of hepatocellular carcinoma using a sensitive assay for serum des-gamma-carboxy prothrombin: a prospective study. Hepatogastroenterology 2002;49:235-238.

-38 Ishii M, Gama H, Chida N, Ueno Y, Shinzawa H, Takagi T, et al: Simultaneous measurements of serum alphafetoprotein and protein induced by vitamin K absence for detecting hepatocellular carcinoma. South Tohoku District Study Group. Am J Gastroenterol 2000;95:1036-1040.

-39 Shimauchi Y, Tanaka M, Kuromatsu R, Ogata R, Tateishi Y, Itano S, et al: A simultaneous monitoring of Lens culinaris agglutinin A-reactive alpha-fetoprotein and des-gamma-carboxy prothrombin as an early diagnosis of hepatocellular carcinoma in the follow-up of cirrhotic patients. Oncol Rep 2000;7:249-256.

$>40$ Durazo FA, Blatt LM, Corey WG, Lin JH, Han S, Saab S, et al: Des-gamma-carboxyprothrombin, alpha-fetoprotein and AFP-L3 in patients with chronic hepatitis, cirrhosis and hepatocellular carcinoma. J Gastroenterol Hepatol 2008;23:1541-1548.

-41 Marrero JA, Feng Z, Wang Y, Nguyen MH, Befeler AS, Roberts LR, et al: Alpha-fetoprotein, des-gamma carboxyprothrombin, and lectin-bound alpha-fetoprotein in early hepatocellular carcinoma. Gastroenterology 2009;137:110-118.

-42 Colli A, Fraquelli M, Casazza G, Massironi S, Colucci A, Conte D, et al: Accuracy of ultrasonography, spiral CT, magnetic resonance, and alpha-fetoprotein in diagnosing hepatocellular carcinoma: a systematic review. Am J Gastroenterol 2006;101:513-523.

43 Ryder SD: Guidelines for the diagnosis and treatment of hepatocellular carcinoma (HCC) in adults. Gut 2003;52(suppl 3):iii1-iii8.

$\checkmark 44$ Song do S, Bae SH: Changes of guidelines diagnosing hepatocellular carcinoma during the last ten-year period. Clin Mol Hepatol 2012;18:258-267.

$\checkmark 45$ Nazir RT, Sharif MA, Iqbal M, Amin MS: Diagnostic accuracy of fine needle aspiration cytology in hepatic tumours. J Coll Physicians Surg Pak 2010;20:373-376.

46 Tunio MA: Diagnostic accuracy of fine needle aspiration cytology in hepatic tumours. J Coll Physicians Surg Pak 2010;20:776-777, author reply 7-8.

47 Silva MA, Hegab B, Hyde C, Guo B, Buckels JA, Mirza DF: Needle track seeding following biopsy of liver lesions in the diagnosis of hepatocellular cancer: a systematic review and meta-analysis. Gut 2008;57:1592-1596.

48 Young AL, Lodge JP: Needle-track seeding following biopsy of liver lesions in the diagnosis of hepatocellular cancer: a systematic review and meta-analysis. Gut 2009;58:887-888.

-49 Yoshizawa H, Tanaka J, Miyakawa Y: National prevention of hepatocellular carcinoma in Japan based on epidemiology of hepatitis C virus infection in the general population. Intervirology 2006;49:7-17.

50 Yoshizawa H, Tanaka J: A national project for the management of viral hepatitis toward prevention of hepatocellular carcinoma in Japan; in Morrissey RF (ed): International Kilmer Conference Proceedings. Laval, Polyscience Publications, 2004, vol 8, pp 247-264.

51 Kokudo N, Makuuchi M: Evidence-based clinical practice guidelines for hepatocellular carcinoma in Japan: the J-HCC guidelines. J Gastroenterol 2009;44(suppl 19):119-121.

52 Clinical Practice Guidelines for Hepatocellular Carcinoma - The Japan Society of Hepatology 2009 update. Hepatol Res 2010;40(suppl 1):2-144.

53 Kudo M, Izumi N, Kokudo N, Matsui O, Sakamoto M, Nakashima O, et al: Management of hepatocellular carcinoma in Japan: Consensus-Based Clinical Practice Guidelines proposed by the Japan Society of Hepatology (JSH) 2010 updated version. Dig Dis 2011;29:339-364.

54 Kudo M: Real practice of hepatocellular carcinoma in Japan: conclusions of the Japan Society of Hepatology 2009 Kobe Congress. Oncology 2010;78(suppl 1):180-188.

55 Lim JH, Kim CK, Lee WJ, Park CK, Koh KC, Paik SW, et al: Detection of hepatocellular carcinomas and dysplastic nodules in cirrhotic livers: accuracy of helical CT in transplant patients. AJR Am J Roentgenol 2000;175:693-698.

56 Peterson MS, Baron RL, Marsh JW Jr, Oliver JH 3rd, Confer SR, Hunt LE: Pretransplantation surveillance for possible hepatocellular carcinoma in patients with cirrhosis: epidemiology and CT-based tumor detection rate in 430 cases with surgical pathologic correlation. Radiology 2000;217:743-749.

-57 Kubota K, Hisa N, Nishikawa T, Fujiwara Y, Murata Y, Itoh S, et al: Evaluation of hepatocellular carcinoma after treatment with transcatheter arterial chemoembolization: comparison of Lipiodol-CT, power Doppler sonography, and dynamic MRI. Abdom Imaging 2001;26:184-190.

-58 Rode A, Bancel B, Douek P, Chevallier M, Vilgrain V, Picaud G, et al: Small nodule detection in cirrhotic livers: evaluation with US, spiral CT, and MRI and correlation with pathologic examination of explanted liver. J Comput Assist Tomogr 2001;25:327-336.

-59 Zhang BH, Yang BH, Tang ZY. Randomized controlled trial of screening for hepatocellular carcinoma. J Cancer Res Clin Oncol 2004;130:417-422. 
60 Song PP, Gao JJ, Kokudo N, Dong JH, Tang W: 'Knowledge into action' - exploration of an appropriate approach for constructing evidence-based clinical practice guidelines for hepatocellular carcinoma. Biosci Trends 2012;6:147-152.

61 Cui R, Wang B, Ding H, Shen H, Li Y, Chen X: Usefulness of determining a protein induced by vitamin K absence in detection of hepatocellular carcinoma. Chin Med J (Engl) 2002;115:42-45.

62 Cui R, He J, Zhang F, Wang B, Ding H, Shen H, et al: Diagnostic value of protein induced by vitamin K absence (PIVKAII) and hepatoma-specific band of serum gamma-glutamyl transferase (GGTII) as hepatocellular carcinoma markers complementary to alpha-fetoprotein. Br J Cancer 2003;88:1878-1882.

63 Marrero JA: Screening tests for hepatocellular carcinoma. Clin Liver Dis 2005;9:235-251.

64 Kew MC, Purves LR, Bersohn I: Serum alpha-fetoprotein levels in acute viral hepatitis. Gut 1973;14:939-942.

65 Eleftheriou N, Heathcote J, Thomas HC, Sherlock S: Serum alpha-fetoprotein levels in patients with acute and chronic liver disease. Relation to hepatocellular regeneration and development of primary liver cell carcinoma. J Clin Pathol 1977;30:704-708.

66 Alpert E, Feller ER: Alpha-fetoprotein (AFP) in benign liver disease. Evidence that normal liver regeneration does not induce AFP synthesis. Gastroenterology 1978;74:856-858.

67 Taketa K: Alpha-fetoprotein: reevaluation in hepatology. Hepatology 1990;12:1420-1432.

68 Mita Y, Aoyagi Y, Yanagi M, Suda T, Suzuki Y, Asakura H: The usefulness of determining des-gamma-carboxy prothrombin by sensitive enzyme immunoassay in the early diagnosis of patients with hepatocellular carcinoma. Cancer 1998;82:1643-1648.

69 Liebman HA, Furie BC, Tong MJ, Blanchard RA, Lo KJ, Lee SD, et al: Des-gamma-carboxy (abnormal) prothrombin as a serum marker of primary hepatocellular carcinoma. N Engl J Med 1984;310:1427-1431.

-70 Marrero JA, Su GL, Wei W, Emick D, Conjeevaram HS, Fontana RJ, et al: Des-gamma carboxyprothrombin can differentiate hepatocellular carcinoma from nonmalignant chronic liver disease in American patients. Hepatology 2003;37:1114-1121.

-71 Nomura F, Ishijima M, Kuwa K, Tanaka N, Nakai T, Ohnishi K: Serum des-gamma-carboxy prothrombin levels determined by a new generation of sensitive immunoassays in patients with small-sized hepatocellular carcinoma. Am J Gastroenterol 1999;94:650-654.

-72 Tanaka Y, Kashiwagi T, Tsutsumi H, Nagasawa M, Toyama T, Ozaki S, et al: Sensitive measurement of serum abnormal prothrombin (PIVKA-II) as a marker of hepatocellular carcinoma. Hepatogastroenterology 1999; 46:2464-2468.

73 Lamerz R, Runge M, Stieber P, Meissner E: Use of serum PIVKA-II (DCP) determination for differentiation between benign and malignant liver diseases. Anticancer Res 1999;19:2489-2493.

74 Suehiro T, Sugimachi K, Matsumata T, Itasaka H, Taketomi A, Maeda T: Protein induced by vitamin K absence or antagonist II as a prognostic marker in hepatocellular carcinoma. Comparison with alpha-fetoprotein. Cancer 1994;73:2464-2471.

-75 Volk ML, Hernandez JC, Su GL, Lok AS, Marrero JA: Risk factors for hepatocellular carcinoma may impair the performance of biomarkers: a comparison of AFP, DCP, and AFP-L3. Cancer Biomark 2007;3:79-87.

-76 Beale G, Chattopadhyay D, Gray J, Stewart S, Hudson M, Day C, et al: AFP, PIVKAII, GP3, SCCA-1 and follisatin as surveillance biomarkers for hepatocellular cancer in non-alcoholic and alcoholic fatty liver disease. BMC Cancer 2008;8:200.

77 Tang W, Miki K, Kokudo N, Sugawara Y, Imamura H, Minagawa M, et al: Des-gamma-carboxy prothrombin in cancer and non-cancer liver tissue of patients with hepatocellular carcinoma. Int J Oncol 2003;22:969975.

78 Yuan LW, Tang W, Kokudo N, Sugawara Y, Karako H, Hasegawa K, et al: Measurement of des-gamma-carboxy prothrombin levels in cancer and non-cancer tissue in patients with hepatocellular carcinoma. Oncol Rep 2004;12:269-273.

-79 Tang W, Kokudo N, Sugawara Y, Guo Q, Imamura H, Sano K, et al: Des-gamma-carboxyprothrombin expression in cancer and/or non-cancer liver tissues: association with survival of patients with resectable hepatocellular carcinoma. Oncol Rep 2005;13:25-30.

80 Xiang CH, Zhang W, Inagaki Y, Zhang KM, Nakano Y, Kokudo N, et al: Measurement of serum and tissue des-gamma-carboxyprothrombin in resectable hepatocellular carcinoma. Anticancer Res 2008;28:22192224.

81 Inagaki Y, Tang W, Xu H, Wang F, Nakata M, Sugawara Y, et al: Des-gamma-carboxyprothrombin: clinical effectiveness and biochemical importance. Biosci Trends 2008;2:53-60.

82 Inagaki Y, Tang W, Makuuchi M, Hasegawa K, Sugawara Y, Kokudo N: Clinical and molecular insights into the hepatocellular carcinoma tumour marker des-gamma-carboxy prothrombin. Liver Int 2011;31:22-35.

83 Inagaki Y, Xu HL, Hasegawa K, Aoki T, Beck Y, Sugawara Y, et al: Des-gamma-carboxyprothrombin in patients with hepatocellular carcinoma and liver cirrhosis. J Dig Dis 2011;12:481-488.

84 Inagaki Y, Qi F, Gao J, Qu X, Hasegawa K, Sugawara Y, et al: Effect of c-Met inhibitor SU11274 on hepatocellular carcinoma cell growth. Biosci Trends 2011;5:52-56.

-85 Gao JJ, Inagaki Y, Xue X, Qu XJ, Tang W: c-Met: A potential therapeutic target for hepatocellular carcinoma. Drug Discov Ther 2011;5:2-11. 